\title{
Forelimb Myology of the Golden Pheasant (Chrysolophus pictus)
}

\author{
Miología del Miembro Anterior del Faisán Dorado (Chrysolophus pictus)
}

\author{
Zihui Zhang* \& Yan Yang*
}

ZHANG, Z. \& YANG, Y. Forelimb Myology of the Golden Pheasant (Chrysolophus pictus). Int. J. Morphol., 31(4):1482-1490, 2013.

SUMMARY: Morphological work on the appendicular myology of birds forms the basis for comparative, functional and systematic studies, but our knowledge of the descriptive anatomy of birds is still very incomplete. The musculature of the wing muscles of the Golden Pheasant (Chrysolophus pictus), an endemic species of China, is studied in detail. All wing muscles are present as in other Galliformes. Myological characteristics including the absence of a deep layer of M. pectoralis pars thoracicus, well development of anterbrachial muscles, as well as the occurrence of a distinct fleshy slip from the proximal belly of M. biceps brachii, are suggested to be associated with its flapping flight. This paper is the prelude to functional analysis on muscle architecture in this species and may serve as a basis for future taxonomic comparisons.

KEY WORDS: Golden Pheasant; Forelimb musculature; Anatomy; Flight style; Function.

\section{INTRODUCTION}

The Golden Pheasant (Chrysolophus pictus) is an endemic pheasant of China which is distributed in central provinces (Zheng \& Wang, 1998; Lei \& Lu, 2006). It has decreased in number mainly due to rampant hunting for the use of their beautiful feathers and special function in traditional Chinese medicine (Wu et al., 2010). Preliminary works on ecology, anatomy, physiology, genetic structure, phylogenetic analysis have been carried out, but a detailed investigation of its myology was lacking until now.

Studies of the appendicular myology of birds have been undertaken for over a century, but our knowledge of the comparative anatomy of birds is still very incomplete. Berger considered "descriptions of the complete appendicular myology of all genera in different families of birds ..." to be a major area of needed research (George \& Berger, 1966). Gross myological differences and similarities may serve as a basis for study of the functional morphology of locomotion, as well as phylogenetics and systematics at various taxonomic levels (Hudson et al., 1969; Vanden Berge, 1970; Zusi \& Bentz, 1982; McKitrick, 1991; Raikow, 1994). The most comprehensive work on the pectoral myology of galliform birds was by Hudson et al. (1964, 1966), who investigated a sample of specimens representing all families and subfamilies in this order, and made both qualitative and numerical analyses. As they stated in a previous paper that "the greatest handicap to such a study is the extreme difficulty of obtaining adequate material, especially of types found only in remote parts of the world" (Hudson et al., 1959). One may find that most of the genera and species not included in their samples are from China, which are rich in pheasant diversity and possess many endemic species. Myological work on the endemic pheasants of China will be a necessary supplement to the morphological database, and provide reference for future comparative, functional and systematic studies.

Many factors contribute to muscle function, including fiber arrangement, fiber type, number of joints crossed, and the synergistic actions of muscle groups. These factors are not considered here, and this study provides only a first detailed description of the musculature of the pectoral limb of the Golden Pheasant, as a basis for functional and systematic studies.

\section{MATERIAL AND METHOD}

Four adult males were obtained from Beijing Wildlife Rescue and Rehabilitation Center, and one female was commercially purchased. All were stored in $75 \%$ ethanol for the dissections that were performed from proximal to distal, from superficial to deep. The description included 
the location and nature (fleshy, tendinous) of the origin and insertion, fiber architecture (e.g., bipennate, parallel), and the relation with adjacent muscles. The figures were drawn by hand. Nomenclature for the musculature and the various bony structures to which the muscles are attached follows that of Nomina Anatomica Avium (Baumel et al., 1993).

\section{RESULTS}

M. latissimus dorsi pars cranialis (Figs. 1 and 4: LDCR) is one of the superficial muscles on the dorsal surface of the shoulder. It arises from the processus spinosus of the last cervical vertebra and the first thoracic vertebra. The parallel-fibered belly extends laterally between the scapular and humeral heads of $M$. triceps brachii to its fleshy insertion on the caudal surface of the proximal humerus.

M. latissimus dorsi pars caudalis (Fig. 1: LDCA) is a mainly tendinous muscle lies caudally to $M$. latissimus dorsi cranialis. It arises mainly by a thin aponeurosis from the middorsal line between the origin of M. latissimus dorsi cranialis and the anterior end of ilium. The belly extends craniolaterally and continues with a very extensive tendinous sheet near axillary region. There is no distinct tendon of insertion, and any specific point of insertion on the humerus.

\section{M. latissimus dorsi pars metapatagialis (Fig. 1:} LDM) is weak and closely attached to the skin. It arises by fascia from the middorsal line near the anterior end of the ilium, and extends craniolaterally above the belly of $M$. latissimus dorsi caudalis to the common insertion with $\mathrm{M}$. serratus superficialis pars metapatagialis on the caudomedial edge of the humeral feather tract.

M. rhomboideus superficialis (Figs. 1 and 2: RS) is an extremely wide but very short muscle which lies deep to M. latissimus dorsi caudalis. It arises by an aponeurosis from the processus spinosus of the last three cervical vertebrae and the first three thoracic vertebrae. The parallel-fibered belly extends craniolaterally to the fleshy insertion on the dorsomedial edge of about the proximal three-fourths of the scapular shaft.

M. rhomboideus profundus (Fig. 2: RP) is concealed by $M$. rhomboideus superficialis. It arises mostly fleshy from the processus spinosus of the last cervical vertebra and the first three thoracic vertebrae. The very wide but short belly extends caudolaterally to the fleshy insertion on the

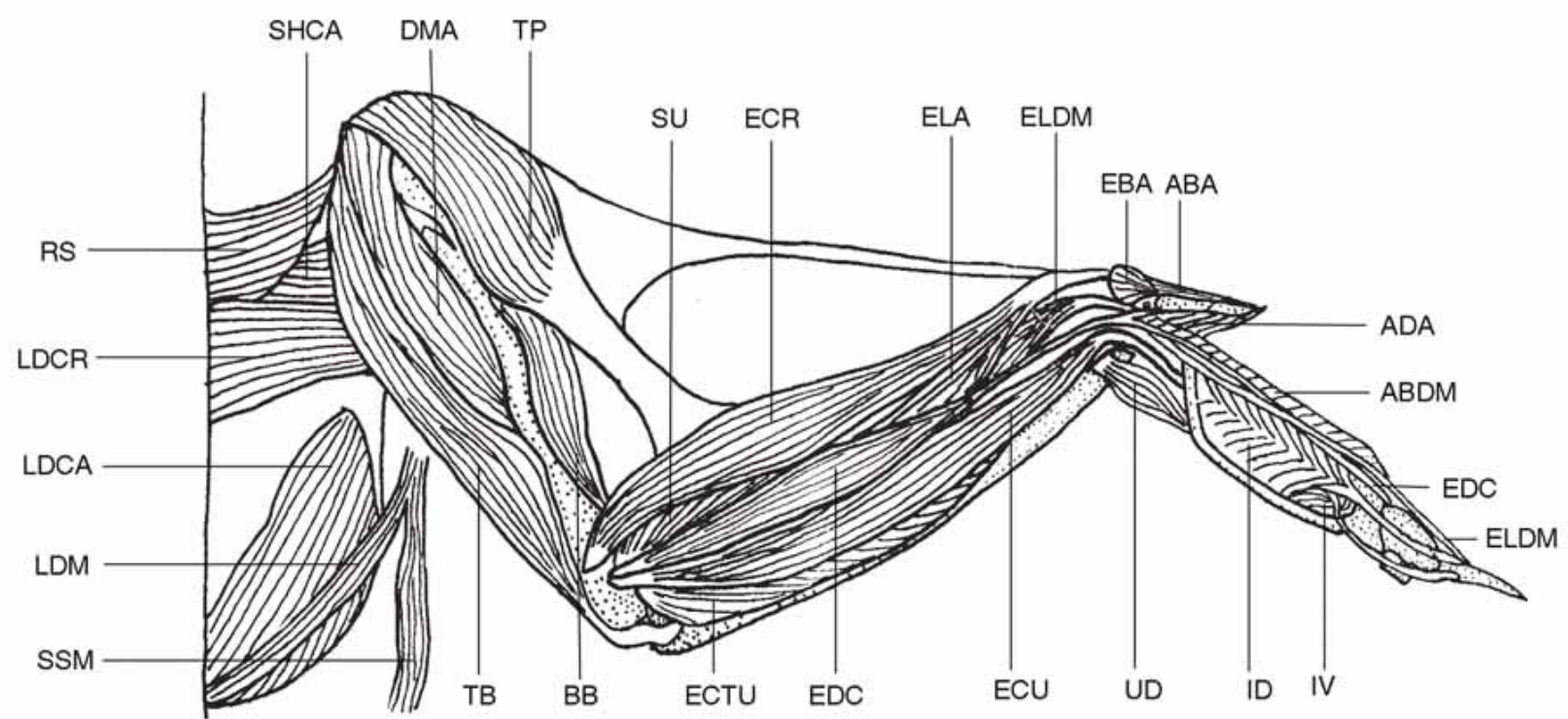

Fig. 1. Dorsal view of the superficial muscles of the Golden Pheasant. ABA, M. abductor alulae; ABDM, M. abductor digiti majoris; ADA, M. adductor alulae; BB, M. biceps brachii; DMA, M. deltoideus major; EBA, M. extensor brevis alulae; ECR, M. extensor carpi radialis; ECTU, M. ectepicondylo ulnaris; ECU, M. extensor carpi ulnaris; EDC, M. extensor digitorum communis; ELA, M. extensor longus alulae; ELDM, M. extensor longus digiti majoris; ID, M. interosseus dorsalis; IV, M. interosseus ventralis; LDCA, M. latissimus dorsi pars caudalis; LDCR, M. latissimus dorsi pars cranialis; LDM, M. latissimus dorsi pars metapatagialis; RS, M. rhomboideus superficialis; SHCA, M. scapulohumeralis caudalis; SSM, M. serratus superficialis pars metapatagialis; SU, M. supinator; TB, M. triceps brachii; TP, M. tensor propatagialis; UD, M. ulnometacarpalis dorsalis. 
ventromedial edge of about the caudal two-thirds of the scapular shaft.

M. serratus superficialis pars cranialis is located on the lateral surface of the thorax, with other three serratus muscles. This small, flat muscle arises partly fleshy, from the lateral surface of the first two cervical ribs, at about the level of the uncinate process. The parallel-fibered belly extends craniodorsally to inserts on the dorsomedial surface of the proximal scapula by a flat tendon.

M. serratus superficialis pars caudalis is a more or less triangular muscle arising partly fleshy from the lateral surface of the second, third and fourth thoracic ribs, just ventral to the uncinate processes, and from the fibrous tissue between them. The single belly extends dorsally and a little caudally to the mainly fleshy insertion on the medial surface of the scapula.

M. serratus superficialis pars metapatagialis (Figs. 1 and 4: SSM) is a ribbon-shaped muscle originating from a small area on the lateral surfaceof the third and the fourth thoracic ribs. The parallel-fibered belly extends dorsally toward the axillary region where it turns abruptly dorsolaterally into the metapatagium to insert on the caudomedial edge of the humeral feather tract.

M. serratus profundus originates partly fleshy from the last two cervical ribs, the first thoracic rib and the fibrous membrane between these ribs. The area of origin is dorsal to the level of the uncinate processes. Insertion is fleshy along a narrow line on the medial surface of the scapula, between the insertions of $M$. serratus superficialis cranialis and $M$. serratus superficialis caudalis.

M. scapulohumeralis cranialis is a small, short and entirely fleshy muscle arising from a small area on the ventrolateral surface of the proximal scapula, a short distance behind the glenoid fossa. The belly extends caudolaterally, directly behind the shoulder joint capsule, to the fleshy insertion on the fossa pneumotricipitalis at the caudal aspect of the proximal humerus.

M. scapulohumeralis caudalis (Figs. 1, 2 and 4: SHCA) is a rather flat, powerful muscle on the dorsal aspect of the shoulder, arising fleshy from the dorsal and lateral

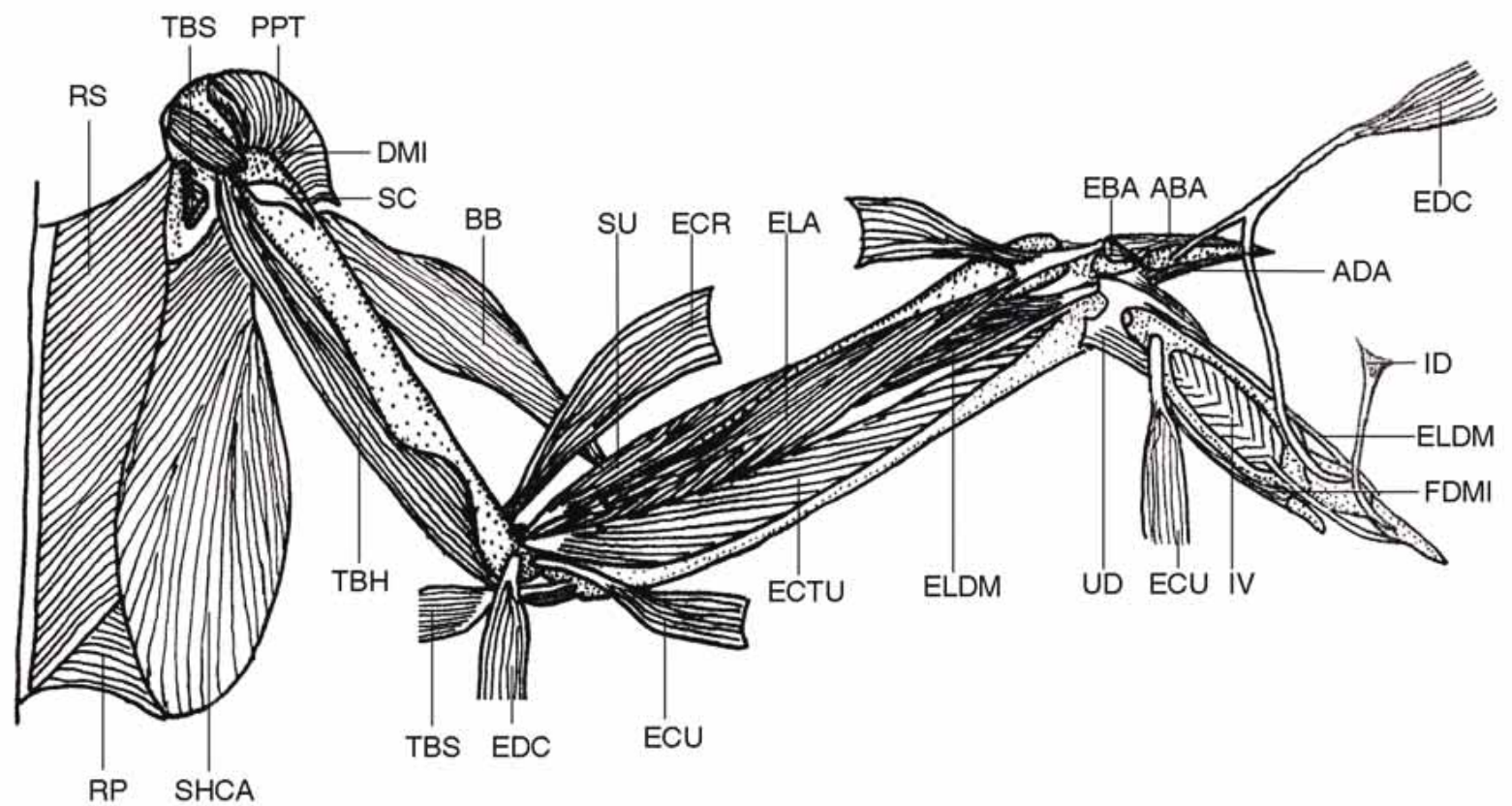

Fig. 2. Dorsal view of the deep muscles of the Golden Pheasant. ABA, M. abductor alulae; ADA, M. adductor alulae; BB, M. biceps brachii; DMI, M. deltoideus minor; EBA, M. extensor brevis alulae; ECR, M. extensor carpi radialis; ECTU, $M$. ectepicondylo ulnaris; ECU, M. extensor carpi ulnaris; EDC, M. extensor digitorum communis; ELA, M. extensor longus alulae; ELDM, M. extensor longus digiti majoris; FDMI, M. flexor digiti minoris; ID, M. interosseus dorsalis; IV, M. interosseus ventralis; PPT, M. pectoralis pars thoracica; RP, M. rhomboideus profundus; RS, M. rhomboideus superficialis; SC, M. supracoracoideus; SHCA, M. scapulohumeralis caudalis; SU, M. supinator; TBH, humeral head of M. triceps brachii; TBS, scapular head of $M$. triceps brachii; UD, M. ulnometacarpalis dorsalis. 
surfaces of almost the entire scapular shaft. The muscle fibers converge craniolaterally to a very short tendon which inserts on the caudoventral of the proximal humerus.

M. pectoralis pars thoracicus (Figs. 3 and 4: PPT) is the largest wing muscle. The bulky belly has an extensive fleshy origin from the crista sterni ventral to that of the $M$. supracoracoideus, the caudolateral surface of the clavicle, the craniolateral surface of the dorsal portion of membrana sternocoracoclavicularis, the outer surface of membranae incisurarum sterni, and the lateral surface of the sternal parts of the first four thoracic ribs. The fibers converge craniodorsally to insert by a mainly tendinous attachment on the cranial surface of the crista deltopectoralis of the proximal humerus, and cover the strong origin of M. biceps brachii.

M. pectoralis pars propatagialis (Fig. 3: PPP) is tendinous and composed of two parts: pars longus and brevis. Pars longus derives from the craniolateral surface of the belly of $M$. pectoralis pars thoracicus, and attaches to the cranioventral surface of the belly of $M$. tensor propatagialis. Pars brevis is from the extreme lateral edge of the belly of $M$. pectoralis pars thoracicus, and fuses firmly with the biceps slip of $M$. biceps brachii.

M. supracoracoideus (Figs. 2 and 4: SC) lies directly dorsal to M. pectoralis pars thoracica, and consists of two distinct parts. The large ventral head originates by fleshy fibers from a large area along the dorsal part of the lateral surface of the keel, the ventral surface of the narrow median part of the sternum, the caudoventral portion of membrana sternocoracoclavicularis and the medial half of the fibrous membrane between trabeculae intermedia and mediana. The bipennate belly converges on a powerful tendon, and inserts on the tuberculum dorsale of the proximal humerus after passing through the canalis triosseus to the dorsal surface of the shoulder joint. The smaller dorsal (deep) head arises from the rostrum sterni, the craniomedial surface of the coracoid, and caudolateral surface of the dorsal portion of membrana sternocoracoclavicularis. The tendon lies medially to that of the ventral head when passing through canalis triosseus to its dorsal attachment on the proximal humerus.

M. coracobrachialis cranialis is a small, mainly tendious muscle, lying directly on the ventral side of the shoulder joint. It arises from the craniodorsal apex of the coracoid and inserts on a shallow excavation at the cranial aspect of the proximal humerus.

M. coracobrachialis caudalis (Fig. 4: CBCA) is a stout, bipennate muscle. It arises fleshy from the ventrolateral surface of the coracoid, the base of the processus craniolateralis sterni, and the adjacent lateral surface of corpus sterni. The short and stout insertion tendon attaches on the tuberculum ventrale of the proximal humerus.

M. sternocoracoideus is a deeply situated, somewhat fan-shaped muscle locating on the dorsal side of the proximal end of the coracoid. The fleshy origin is from the medial, cranial, and part of the lateral surfaces of the processus craniolateralis sterni, and the sternal ends of the first two thoracic ribs. The muscle fibers extend craniodorsally to a long triangular depression on the dorsal surface of about the proximal half of the coracoid.

M. subcoracoideus (Fig. 4: SCO) is a powerful, fleshy muscle arising from the dorsomedial surface of the coracoid, the lateral surface of the rostrum sterni, and the dorsal surface of the adjacent ligamentum sternocoracoclavicularis. Near the shoulder joint it meets and fuses more or less with $M$. subscapularis. The common tendinous insertion is on the tuberculum ventrale of the proximal humerus.

M. subscapularis is divided into internal and external heads, which are separated by the insertion tendon of $M$. serratus superficialis pars cranialis. The larger pars interna arises by fleshy fibers from the medial surface of the proximal scapula, and pars externa is tendinous from the ventral surface of the scapula. The two parts of $M$. subscapularis share a short common tendon with $M$. subcoracoideus.

M. tensor propatagialis (Figs. 1 and 3: TP) is consist of two parts: pars longa and pars brevis. The single, large belly arises tendinous from a small area on the craniodorsal apex of the coracoid toward the medial side and from the adjacent ligamentum acrocoraco-claviculare. The distal end of the belly connects with a wide, thin tendon which represents pars brevis, inserting on the cranioproximal aspect of the belly of M. extensor carpi radialis. Pars longa ends on a tendon extending distally along the leading edge of the propatagium to the processus extensorius of the alular metacarpal. Except the distal end, the entire tendon of pars longa is broad and elastic, and there is a sesamoid at the wrist.

M. deltoideus major (Fig. 1: DMA) is a superficial muscle on the dorsal aspect of the proximal half of the brachium. It arises by fleshy fibers from the medial surface of the head of the clavicle and the adjacent scapula and coracoid. The belly gives rise to a large and broad tendon at about the middle of the humerus to insert on the caudodorsal surface of the shaft. 
M. deltoideus minor (Fig. 2: DMI) is a slender, parallel-fibered muscle on the dorsal surface of the shoulder joint. It arises fleshy from the dorsal surface of the distal end of the coracoid and the adjacent part of the scapula. Tendinous insertion is on the proximal end of the tuberculum dorsale of the humerus.

M. biceps brachii (Figs. 1 to 4: BB) is a superficial muscle on the cranial surface of the brachium, originating by a broad, heavy tendinous sheet from the crista bicipitalis of the proximal humerus and the craniolateral surface of the dorsal apex of the coracoid. The powerful, single belly extends toward the elbow along the cranial side of the brachium. Near the distal end of the humerus, the tendon of insertion is formed and bifurcated, attaching to the tuberculum bicipitale of the proximal radius, and the ventrocranial of the proximal ulna, respectively. The proximal belly of $M$. biceps brachii gives from the craniodorsal aspect a fleshy slip (Fig. 3: BBS) that extends dorsally and distally into the propatagium, and finally inserts tendinously on the insertion tendon of $M$. tensor propatagialis pars longa.
M. triceps brachii (Figs. 1 and 3: TB) is a large muscle on the caudal aspect of the brachium, consisting of two welldefined parts. The scapular head (Figs. 2, 4: TBS) arises partly fleshy from a small area on the dorsal and lateral surfaces of the proximal scapula. The humeral head (Figs. 2 and 4: TBH) is much larger, originating mainly by fleshy fibers from a very extensive area on the ventral and caudal surfaces of the entire length of humerus. The common insertion of $M$. triceps brachii is by a short, strong tendinous sheet on the dorsal and caudal surfaces of the olecranon of the ulna.

M. expansor secondariorum (Fig. 3: ES) consists of two parts. A very short, fan-shaped, distal head originates tendinously from the epicondylus ventralis humeri and the adjacent joint capsule, and inserts on the ventral surface of the calamus of four remiges at the elbow. The slender belly of the proximal head, which is from the quills of three remiges, extends toward the axillary region in the metapatagium for a short distance, and then continues proximally as a narrow tendon to insert on dorsal edge of the belly of M. subcoracoideus.

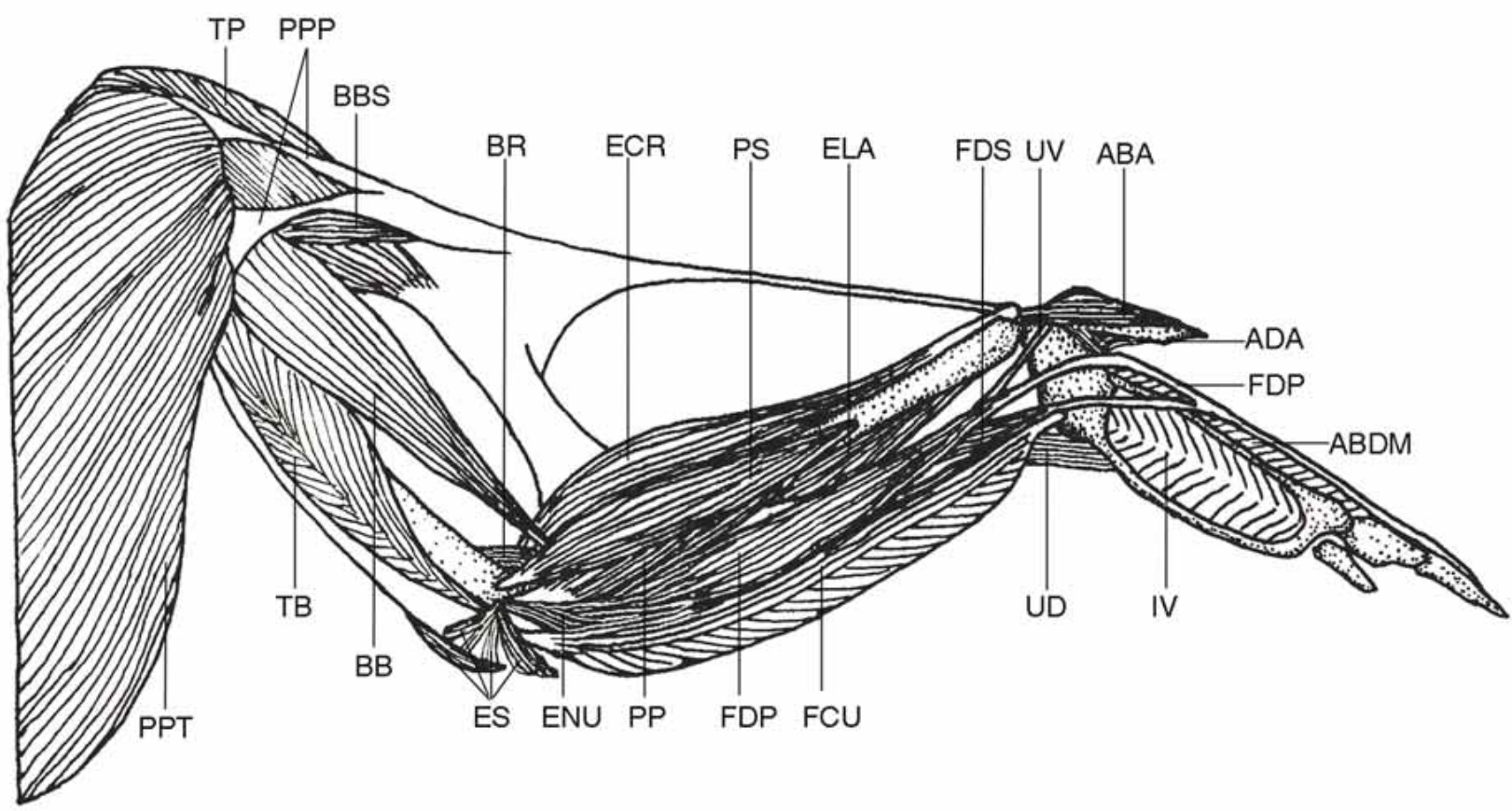

Fig. 3. Ventral view of the superficial muscles of the Golden Pheasant. ABA, M. abductor alulae; ABDM, abductor digiti majoris; ADA, M. adductor alulae; BB, M. biceps brachii; BBS, M. biceps brachii slip; BR, M. brachialis; ECR, M. extensor carpi radialis; ELA, M. extensor longus alulae; ENU, M. Entepicondylo ulnaris; ES, M. expansor secondariorum; FCU, M. flexor carpi ulnaris; FDP, M. flexor digitorum profundus; FDS, M. flexor digitorum superficialis; IV, M. interosseus ventralis; PP, M. pronator profundus; PPP, M. pectoralis pars propatagialis; PPT, M. pectoralis pars thoracica; PS, M. pronator superficialis; TB, M. triceps brachii; TP, M. tensor propatagialis; UD, M. ulnometacarpalis dorsalis; UV, M. ulnometacarpalis ventralis. 
M. brachialis (Figs. 3 and 4: BR) is a short, straplike muscle. It arises from fossa $M$. brachialis and inserts fleshy on impressio M. brachialis of the proximal ulna.

M. pronator superficialis (Figs. 3 and 4: PS) is in superficial view on the cranioventral surface of the forearm. It is partly fleshy from the proximal end of epicondylus ventralis humeri. The belly occupies the proximal two-thirds of the radius, and attaches to the bone by a long, narrow line on the cranioventral surface.

M. pronator profundus (Figs. 3 and 4: PP) is deep to M. pronator superficialis and arises by a stout tendon from the distal end of epicondylus ventralis humeri. Insertion is mainly fleshy on the caudoventral surface of about the proximal two-thirds of the radius.

M. entepicondylo ulnaris (Figs. 3 and 4: ENU) arises tendinous from the distal end of the epicondylus ventralis humeri. The belly extends caudodistally to its insertion on the ventral surface of the proximal one-half of the ulna. There is a slight overlap between the distal end of M. entepicondylo ulnaris and the proximal end of $M$. ulnometacarpalis ventralis.

M. flexor carpi ulnaris (Figs. 3 and 4: FCU) is a large superficial muscle occupying the caudoventral surface of the nearly entire length of forearm. It originates by a short, powerful tendon from the epicondylus ventralis humeri. The caudal portion of the belly contacts strongly with the base of the secondary quills, and the proximal belly embeds a short and flat sesamoid. Insertion is by a very short, strong tendon on the caudoventral surface of the ulnare.

M. flexor digitorum superficialis (Figs. 3 and 4: FDS) arises fleshy from the dorsal fold of the fibrous sheath enclosing it and M. flexor carpi ulnaris. The belly confines to the distal half of the forearm. The tendon meets that of $M$. flexor digitorum profundus at about the proximal end of the major metacarpal. They are tightly connected by fibrous tissue when extending distally to their common attachment on the cranioventral edge of the proximal end of the second phalanx of the major digit.

M. flexor digitorum profundus (Figs. 3 and 4: FDP) is a large fusiform muscle which arises fleshy from the ventral surface of the ulna. Near the wrist joint it forms a strong tendon which passes through a fibrous canal, runs around the cranial side of the processus pisiformis and extends distally along the cranioventral margin of the major metacarpal. The tendon inserts on the cranioventral surface of the proximal end of the second phalanx of the major digit, superficial to that of $M$. flexor digitorum superficialis. There is a long sesamoid in the hand.
M. ulnometacarpalis ventralis (Fig. 4: UV) lies deeply in the ventral aspect of the distal half of the forearm, and arises fleshy from the ventral surface of the ulna. The tendon of insertion attaches on the dorsal surface of the base of the alular metacarpal.

M. extensor carpi radialis (Figs. 1 to 3: ECR) is powerful and in superficial view along the leading edge of the ventral surface of antebrachium. It arises partly fleshy from epicondylus dorsalis humeri, dorsal to the area of origin of M. brachialis. Near the distal end of the radius, the belly gives rise to a strong, flattened tendon which fuses with the insertion tendon of M. extensor longus alulae, and finally inserts on processus extensorius of the alular metacarpal.

M. supinator (Figs. 1 and 2: SU) arises by a short tendon from the craniodorsal surface of the epicondylus dorsalis humeri. The insertion is mainly fleshy on the cranial and dorsal surfaces of the proximal three-fifths of the radius.

M. extensor digitorum communis (Figs. 1 and 2: EDC) is in superficial on the dorsal aspect of the forearm, and arises by a short tendon from epicondylus dorsalis humeri. The fusiform belly gives rise to a rather long tendon which bifurcates near the base of the pollex. The short branch inserts on the caudodorsal surface of the proximal end of the alular phalanx, while the main tendon proceeds distally to the craniodorsal side of the proximal end of the first phalanx of the major digit.

M. extensor carpi ulnaris (Figs. 1 and 2: ECU) is in superficial view on the caudodorsal surface of the forearm. The origin is by a short tendon from the dorsal surface of epicondylus dorsalis humeri. The strong tendon of insertion is formed near the distal end of the ulna, and terminates on processus intermetacarpalis of proximal major metacarpal.

M. ectepicondylo ulnaris (Figs. 1 and 2: ECTU) arises by a short, strong tendon from the distal end of epicondylus dorsalis humeri. Most of the belly is concealed by M. extensor carpi ulnaris. The fleshy insertion attaches to the craniodorsal surface of the proximal four-fifths of the ulna.

M. extensor longus alulae (Figs. 1 to 3: ELA) is composed by two fleshy origins. The smaller head arises from the caudal surface of the proximal one-third of the radius and the larger head from the cranial surface of the proximal half of the ulna. The two bellies fuse about midway the forearm and the bipennate belly extends distally along the caudodorsal side of the radius. Near the distal end of the radius the belly terminates in a strong, short tendon which fuses completely with that of $M$. extensor carpi radialis at the wrist. 
M. extensor longus digiti majoris (Figs. 1 and 2: ELDM) is partly exposed in superficial view on the dorsal surface of the distal forearm, and composed of two distinct heads. The proximal head arises fleshy from the caudal surface of the third one-fourth of the radius, and the small distal head is fleshy from the dorsal surface of the distal end of the radius. The belly of the proximal head terminates to a tendon at the distal end of the forearm, which inserts on the cranioventral edge of the proximal end of the second phalanx of the major digit. The short and slender belly of the distal head lies and attaches to the ventral side of the insertion tendon of the proximal head.

M. ulnometacarpalis dorsalis (Figs. 1 to 3: UD) lies in dorsal view of the wrist joint, and arises by a short and wide tendon from the craniodorsal surface of the distal end of the ulna. The belly is divided into dorsal and ventral parts, and inserts on the caudal surface of the proximal minor metacarpal, and the fibrous sheaths of the proximal four primaries respectively.

M. interosseus dorsalis (Figs. 1 and 2: ID) is a bipennate muscle occupying most of the dorsal part of the spatium intermetacarpale. It has a fleshy origin from the caudodorsal surface of major metacarpal and the craniodorsal surface of minor metacarpal. The slender, long tendon inserts on the craniodorsal surface of the base of the second phalanx of the major digit.
M. interosseus ventralis (Figs. 1 to 4: IV) lies ventrally to M. interosseus dorsalis. The origin is fleshy from the ventral surface of the metacarpals bordering the spatium intermetacarpale. The bipennate muscle fibers converge on a central tendon that turns dorsally to emerge on the dorsal surface of the carpometacarpus. Insertion is on the caudodorsal surface of the base of the second phalanx of the major digit.

M. abductor alulae (Figs. 1 to 4: ABA) is the strongest among four muscles attaching to the alular digit. It arises mainly fleshy from the ventral surface of the distal end of the tendon of $\mathrm{M}$. extensor metacarpi radialis, near the base of the alular metacarpal. The insertion is mainly fleshy on the proximoventral surface of the alular phalanx.

M. adductor alulae (Figs. 1 to 4: ADA) is small, and partly fleshy from the cranioventral surface of the proximal end of the major metacarpal. Insertion is almost fleshy on the caudal surface of the alular phalanx along most of its length.

M. extensor brevis alulae (Figs.1 and 2: EBA) arises fleshy from the dorsal surface of the proximal alular metacarpal, and inserts tendinously on the craniodorsal corner of the base of the alular phalanx.

M. flexor alulae is the smallest muscle of the pectoral limb. The origin is fleshy from the ventroproximal surface of

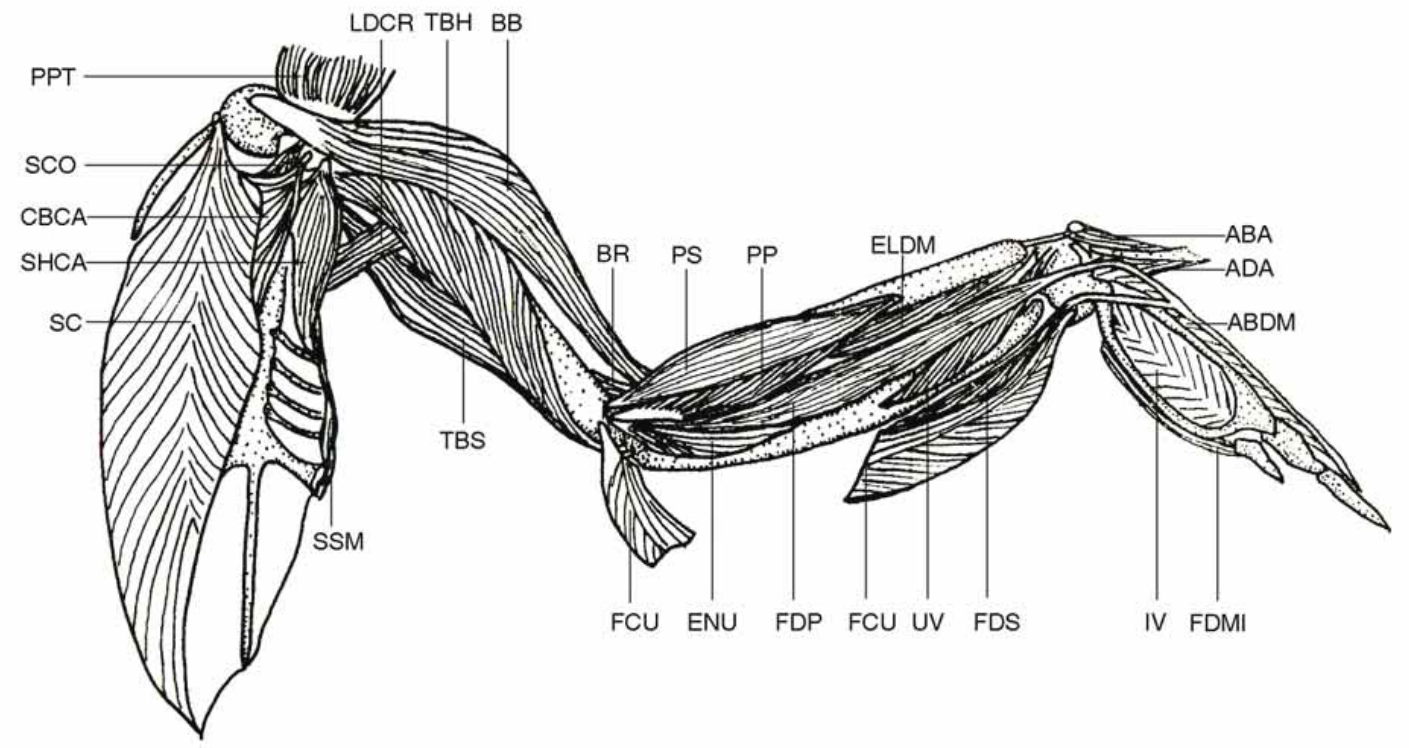

Fig. 4. Ventral view of the deep muscles of the Golden Pheasant. ABA, M. abductor alulae; ABDM, abductor digiti majoris; ADA, M. adductor alulae; BB, M. biceps brachii; BR, M. brachialis; CBCA, M. coracobranchialis caudalis; ELDM, M. extensor longus digiti majoris; ENU, M. Entepicondylo ulnaris; FCU, M. flexor carpi ulnaris; FDP, M. flexor digitorum profundus; FDMI, $M$. flexor digiti minoris; FDS, M. flexor digitorum superficialis; IV, $M$. interosseus ventralis; LDCR. M. latissimus dorsi pars cranialis; PP, M. pronator profundus; PPT, M. pectoralis pars thoracica; PS, M. pronator superficialis; SC, M. supracoracoideus; SCO, M. subcoracoideus; SHCA, M. scapulohumeralis caudalis; SSM, M. serratus superficialis pars metapatagialis; TBH, humeral head of $M$. triceps brachii; TBS, scapular head of $M$. triceps brachii; UV, M. ulnometacarpalis ventralis. 
the alular metacarpal. The belly fills in the groove between the base of alular metacarpal and M. abductor digiti majoris. Insertion is fleshy on the caudoventral surface of the base of the alular phalanx.

M. abductor digiti majoris (Figs. 1, 3 and 4: ABDM) arises fleshy from the cranioventral surface of the entire length of the major metacarpal. It inserts tendinously on the cranioventral surface of the proximal end of the first phalanx of the major digit.

M. flexor digiti minoris (Figs. 2 and 4: FDMI) is a slender muscle arising fleshy from the caudal surface of the minor metacarpal beginning near the insertion of $\mathbf{M}$. ulnometacarpalis dorsalis. Insertion is partly fleshy on a tubercle at the caudal surface of the base of the phalanx.

\section{DISCUSSION}

Appendicular myology is important in classification of birds (George \& Berger). As reported in other galliforms, all wing muscles were found in the Golden Pheasant, and most similar to those of Phasianinae in the slight overlapping between $M$. entepicondylo ulnaris and $M$. ulnimetacarpalis ventralis, partly tendinous origin of $M$. latissimus dorsi pars caudalis, and three sesamoids present in M. tensor propatagialis, $M$. flexor digitorum profundus, and M. flexor carpi ulnaris respectively. These similarities form the basis for classification.

Characteristics of forelimb musculature relate to flight (Meyers, 1992; Corvidae et al., 2006). M. pectoralis pars thoracicus, the largest wing muscle, is generally associated with flight style of birds. In Procellariiformes, Pelecaniformes, Cathartidae, Leptoptilos, Balaeniceps, Mycteria, Ciconia, Grus, the presence and structural arrangement of the deep layer of $M$. pectoralis pars thoracicus, and its tendon, are suggested to be an important factor in stabilization of the brachium and to keep the body from "falling through the wings" during soaring and gliding flight (Kuroda, 1961; Vanden Berge; Fisher, 1946; Meyers). The absence of this portion of the $M$. pectoralis in the Golden Pheasant, as in other galliforms, is suggested to be a myological basis of flapping flight, the only mode of flight (although used very little) that was adopted by this terrestrial bird group in case of escaping predators.

Intrinsic wing muscles assist in modulating wing orientation and controlling wing shape, and probably contribute to adjustments of the wing's performance as an aerofoil (Berg \& Biewener, 2010). Large and fleshy bellies of antebrachial muscles are supposed to correlate with swifter wing strokes and more effective flapping flight (Vanden Berge). Compared with soaring and gliding species of nonpasserine groups, such as Falconiformes and Ciconiiformes, muscles of forearm in the Golden Pheasant are welldeveloped, reflected by the ratio between the belly length to the forearm length. For example, M. extensor carpi radialis, $M m$. pronators superficialis and profundus occupy on the proximal four-fifths and three-fourths of the radius respectively; $M$. flexor carpi ulnaris and $M$. ectepicondylo ulnaris attach nearly the entire length of the ulna. Greater relative length of fleshy belly implies a greater force production or extent of contraction (Berger, 1954; Biewener, 2011). Take-off is key to all flight, especially arduous and explosive from ground as in pheasants; during this phase the stroke plane was tilted steeply downward to push more air rearward to accelerate the bird forward (Berg \& Biewener). The Golden Pheasant is a typical terrestrial bird. It spends the majority of time on the ground and, when threatened, typically runs and hides in dense vegetation rather than flying. When it does fly, its takeoff is explosive and is followed by rapid and swift flapping flight (Lei \& Lu). The well development of $M$. pectoralis pars thoracicus, Mm. pronators superficialis and profundus, M. extensor carpi radialis and $M$. flexor carpi ulnaris is suggested to benefit the take-off, because they are capable of, to some extent, depressing the leading edge of the wing, and contribute to shape change.

In the Golden Pheasant, the proximal belly of $M$. biceps brachii sends a distinct fleshy slip that extends dorsally and distally into the propatagium, and inserts on the tendon of $M$. tensor propatagialis pars longa. Action of the "biceps slip" is probably that of contributing to tension upon the propatagium and, to depress the wing's leading edge. A distinct, well-developed, fleshy slip from $M$. biceps brachii has been found in many other groups of non-passerine birds (George \& Berger), but it is absent in soaring and gliding species of Falconiformes and Ciconiiformes (Vanden Berge; Meyers). From this aspect, one may expect that the presence of a biceps slip might be a myological feature that is associated with the flapping flight of birds.

\section{ACKNOWLEDGEMENTS}

We are grateful to Beijing Wildlife Rescue and Rehabilitation Center for providing anatomical materials.

This work was supported by the National Natural Science Foundation of China ( $\left.N^{\circ} 308700263\right)$. 
ZHANG, Z. \& YANG, Y. Miología del miembro anterior del faisán dorado. (Chrysolophus pictus). Int. J. Morphol., 31(4):1482-1490, 2013.

RESUMEN: El trabajo morfológico en la miología apendicular de las aves constituye la base para los estudios comparativos, funcionales y sistemáticos, sin embargo, nuestro conocimiento de la anatomía descriptiva de las aves es aún muy incompleto. Se estudió en detalle la musculatura de las alas del faisán de oro (Chrysolophus pictus), una especie endémica de China. Todos los músculos de las alas están presentes tal como en otros Galliformes. Características miológicas que se estima están asociadas con su vuelo de aleteo, incluyen la ausencia de una capa profunda de $M$. pectoral pars thoracicus, el buen desarrollo de los músculos anterbrachiales, como también la ocurrencia de un deslizamiento carnoso del vientre proximal de M. bíceps braquial. Este documento es el inicio de un análisis funcional de la arquitectura muscular en esta especie y puede servir de base para futuras comparaciones taxonómicas.

PALABRAS CLAVE: Faisán Dorado; Musculatura anterior; Anatomía; Forma de vuelo; Función.

\section{REFERENCES}

Baumel, J. J.; King, A. S.; Breazile, J. E.; Evans, H. E. \& Vanden Berge, J. C. Handbook of avian anatomy: Nomina Anatomica Avium. 2nd ed. Massachusetts, Publications of the Nuttall Ornithological Club, Cambridge, 1993.

Berg, A. M. \& Biewener, A. A. Wing and body kinematics of takeoff and landing flight in the pigeon (Columba livia). J. Exp. Biol., 213(Pt. 10):1651-8, 2010.

Berger, A. J. The myology of the pectoral appendage of three genera of American cuckoos. University of Michigan Museum of Zoology Miscellaneous Publication, 85:1-35, 1954.

Biewener, A. A. Muscle function in avian flight: achieving power and control. Phil. Trans. R. Soc. B, 366(1570):1496-506, 2011.

Corvidae, E. L.; Bierregaard, R. O. \& Peters, S. E. Comparison of wing morphology in three birds of prey: correlations with differences in flight behavior. J. Morphol., 267(5):612-22, 2006.

Fisher, H. I. Adaptations and comparative anatomy of the locomotor apparatus of New World vultures. Am. Midl. Nat., 35:545$727,1946$.

George, J. C. \& Berger, A. J. Avian myology. New York, Academic Press, 1966.

Hudson, G. E. \& Lanzillotti, P. J. Muscles of the pectoral limb in galliform birds. Am. Midl. Nat., 71:1-113, 1964.

Hudson, G. E.; Lanzillotti, P. J. \& Edwards, G. D. Muscles of the pelvic limb in galliform birds. Am. Midl. Nat., 61:1-67, 1959.

Hudson, G. E.; Parker, R. A.; Berger, A. J. \& Lanzillotti, P. J. A numerical analysis of the modifications of the appendicular muscles in various genera of gallinaceous birds. Am. Midl. Nat., 76:1-73, 1966.

Hudson, G. E.; Hoff, K. M.; Vanden Berge, J. \& Trivette, E. C. A numerical study of the wing and leg muscles of Lari and Alcae. Ibis, 111:454-523, 1969.

Kuroda, N. A note on the pectoral muscles of birds. Auk, 78(2):2613, 1961 .
Lei, F. M. \& Lu, T. C. China Endemic Birds. Beijing, Science Press, 2006.

McKitrick, M. C. Forelimb myology of loons (Gaviiformes), with comments on the relationship of loons and tubenoses (Procellariiformes). Zool. J. Linn. Soc., 102:115-52, 1991

Meyers, R. A. Morphology of the shoulder musculature of the American kestrel, Falco sparverius (Aves), with implications for gliding flight. Zoomorphology, 112:91-103, 1992.

Raikow, R. J. A phylogeny of the woodcreepers (Dendrocolaptinae). Auk, 111:104-14, 1994.

Vanden Berge, J. C. A comparative study of the appendicular musculature of the Order Ciconiiformes. Am. Midl. Nat., 84:289364, 1970.

Wu, B. H.; Li, T. \& Yu, X. P. Winter diet and digestive tract of the Golden Pheasant (Chrysolophus pictus) in the Qinling Mountains, China. Chinese Birds, 1(1):45-50, 2010.

Zheng, G. M. \& Wang, Q. S. China Red Data Book of Endangered Animals (Aves). Beijing, Science Press, 1998.

Zusi, R. L. \& Bentz, G. P. Variation of a muscle in hummingbirds and swifts and its systematic implications. Proc. Biol. Soc. Wash., 95:412-20, 1982

Correspondence to:

Zihui Zhang

Associate Professor, College of Life Sciences

Capital Normal University

Beijing 100048

CHINA

Email: zihuizhang@mail.cnu.edu.cn

Received: 22-08-2013

Accepted: 02-11-201 